\title{
Issues in palliative care for Indigenous communities
}

lan Maddocks and Robert G Rayner

IN PALliative CARE we know that for an individual close to death, the sense of impending loss is often magnified by earlier experiences. Ever since the first intrusions of Europeans into their country, Australian Indigenous communities have lived with the consequences of losing their land, their culture, their autonomy and, in many cases, their language, their dignity and their health. ${ }^{1,2}$

During the 20th century, many Indigenous people also lost their knowledge of family, and their recognised place within it, through the forced removal of children from their parents to placement in institutions or adopting white families. Family strength remains one of the outstanding characteristics of Indigenous life, and a loss of identification with family surely underlies much of the dysfunction of Indigenous society. ${ }^{3}$ Deep emotional scars affect many Indigenous individuals and groups.

\section{Demography and epidemiology}

A person recognised as "Aboriginal" is, by Federal Government definition, of Aboriginal or Torres Strait Islander descent, identifies himself or herself as an Aboriginal person or Torres Strait Islander, or is accepted as such by the Indigenous community in which he or she lives. ${ }^{4}$ At the 2001 census, Indigenous Australians comprised 2.4\% the total Australian population - double the proportion identifying themselves as Indigenous in the 1986 census. Some Indigenous Australians live in rural or remote communities, but the majority live in urban centres, primarily in Queensland and New South Wales. ${ }^{5}$ The Northern Territory has the highest proportion of Indigenous Australians - some $25 \%-30 \%$ of the general population - and at the Royal Darwin Hospital, the Territory's main medical centre, about $65 \%$ of inpatients at any one time are Indigenous.

Indigenous communities in all parts of Australia have a close association with death and dying. In part, this is because death rates for Indigenous Australians are among the highest in the world. This is particularly so in the $25-45-$ year age range, where death rates are 5-8 times those of non-Indigenous Australians, leading to a life expectancy up to 19 years less than non-Indigenous Australians. ${ }^{5}$ An intimate awareness of death and dying is also facilitated by the close involvement of extended family in supporting a patient during terminal illness, and in the ceremonies that

\section{Flinders University, Bedford Park, SA.}

lan Maddocks, MD, FRACP, FAChPM, Emeritus Professor.

Royal Darwin Hospital, Casuarina, NT.

Robert G Rayner, FRACGP, FAChPM, Senior Specialist in Palliative

Medicine.

Reprints will not be available from the authors. Correspondence:

Professor lan Maddocks, 215A The Esplanade, Seacliff, SA 5049.

ian.maddocks@flinders.edu.au

\section{ABSTRACT}

- All Indigenous communities in Australia have a common heritage of loss.

- Indigenous death rates are much higher than those for white Australians.

- Indigenous people use healthcare services reluctantly, and palliative care services rarely.

- Cultural considerations that need to be respected include Indigenous understandings of disease causation, attributions of blame for sickness, the performance of ceremonies after death and the importance of dying on traditional lands.

- The involvement of Indigenous health workers in clinical care increases confidence in the healthcare system as a whole.

MJA 2003; 179: S17-S19

follow a death - gatherings that may extend over several weeks. This can mean that, as one informant suggested, "We have no time to grieve; once one funeral is over we have to prepare for another one".

Excess deaths among Indigenous people are due mainly to circulatory disease, injury, poisoning, respiratory conditions and diabetes. ${ }^{6}$ In traditional times, unexpected death might commonly have been attributed to sorcery; in modern times this understanding remains latent, but there is a greater tendency to blame bad diet, and poisoning by pollutants such as insecticides contaminating grass and water.

\section{Health services}

Except where there are well-established Indigenous medical services, healthcare facilities of all types are used reluctantly. Major conditions such as cancer often come to medical attention only late in the course of the illness. Until recently, public hospital accommodation was segregated, and healthcare services were quite inadequate, particularly given the marked social inequality and the associated poor health status of Indigenous people. ${ }^{7}$

The services offered by Indigenous healthcare providers often have no link with mainstream services and may be unaware of what local palliative care services can offer. Similarly, mainstream providers may have little awareness either of the special needs of Indigenous patients or the services, networks and cultural supports available to them. In many communities, Indigenous people have not accessed palliative care services to any great extent. Many have not heard of palliative care, or associate it only with inpatient care and cancer. ${ }^{8}$ 
Experience of providing palliative care in a centre such as Darwin offers useful insights, though even within the Northern Territory great diversity exists. Weather is a major factor in provision of healthcare services. During the long "wet" season, communities may be isolated by flooding for up to 6 months, and even air access may be impossible for days or weeks at a time. Some Indigenous communities have their own planes, and government-supported services may be able to be maintained by this means. But road access to the more isolated communities, even in the "dry", can prove difficult.

The 50 Aboriginal communities across the Top End range in population from 200 to 2000 persons. In addition, there are many separate outstations formed from established communities for various cultural or clan reasons. An outstation may comprise as few as 15-20 people. Many communities have a clinic staffed by Indigenous health workers, nonIndigenous nurses and either resident or visiting medical officers. Telephone and fax services connect communities to bigger centres. Each community has unique cultural characteristics and often its own language. Some Aboriginal people have fluency in several Indigenous languages, with English only a fourth or fifth language.

To facilitate appropriate clinical interactions, palliative care workers must take note of cultural considerations that affect all clinical encounters, some of which are particularly relevant to situations of death and dying. ${ }^{8}$ Although generalisations should be avoided if possible, some common principles are discussed here.

\section{Communication}

It may be considered impolite or offensive to look directly at an Indigenous person. It will be difficult for an Indigenous person to question a doctor's management, even if it is clearly impractical. Health decisions tend to be a family or community affair. Family structure is complex and governed by recognised obligations and cultural rules. Gender issues are important, with "women's business" and "men's business" being defined and held separate. ${ }^{3}$ This can prevent a practitioner from examining an Indigenous person of the opposite sex. It may be considered more appropriate to talk to individuals other than the patient when discussing that patient's situation. In some communities it is taboo for a son-in-law to talk to his mother-in-law.

Traditional healers have a good understanding of underlying beliefs about health, and may offer treatments with a greater authority than the white healthcare professional can command. Traditional medicines are used in many settings. Indigenous health workers are now widely employed to help liaise with families who are trying to make best use of both traditional and modern medicine. The value of having Indigenous people express their understanding of palliative care in their own way is well demonstrated in a published series of paintings by Aboriginal women artists (Box). ${ }^{9}$

\section{Causes of disease}

Disease in Indigenous communities is often perceived as stemming, in part, from exposure to metaphysical forces, alienation from the homeland (perhaps the result of forced displacement) or some personal deficiency (eg, a ceremonial duty neglected, or a failure to follow a customary rule of behaviour). An attribution of blame may follow, and the saying of "sorry" by persons thought responsible will be regarded as very important; failing that response, a "payback penalty" might be sought, possibly involving physical punishment.

After a death in an Indigenous community, a careful assessment and review of the circumstances and associations of the death - equivalent to the holding of a "coronial inquiry" - may be part of the funeral rituals; some payback may be considered necessary and may be the cause of major clan clashes if another community is involved.

\section{Implications for palliative care}

- Different interpretations of diagnosis and cause may create distrust between staff and patients. Treatments directed at mitigating symptoms, even severe pain, may be perceived as interfering in a necessary process resulting from a culturally-determined sickness. A culturally "safe" approach to pain management is called for. ${ }^{10,11}$

- In seeking to uncover the circumstances and cause of a death, it may be concluded that a carer has been implicated. $\mathrm{He}$ or she may face Indigenous justice, which could mean anything from a short banishment from the community to a spearing. The use of injections by a carer or health worker may raise suspicion of poisoning.

- There is a widely held desire to return to the homeland area to die or to be buried. "Bringing them home" was the powerful phrase coined as a response to the revelations of hurt and alienation inflicted on the "stolen generation" (those children forcibly removed from their parents). "Bringing them home" is also an appropriate term for the strong imperative to return the dead to their place of birth. ${ }^{12}$

\section{Decision-making processes}

The decision-making processes in Indigenous communities are collective and often protracted. Particular people in the patient's "skin" group will make decisions with or on behalf of an individual.

Many factors may be seen as requiring consideration, including the cause of the illness, the patient's role in the community, the possibility of blame, and even who has the right to know the story. An uncle may have more authority with a child than either mother or father. There are proscribed relationships within communities (eg, motherin-law avoiding son-in-law) that must be respected and not invoked. A family meeting may involve up to 30 people, some of whom may need to be brought in from a considerable distance. To achieve an agreed decision within such large groups may take many days. A patient facing surgery may wish to return to the community to discuss options with relatives and receive their permission.

There are "right persons" for the patient to confide in and to advise in decision making. Having such individuals available is important when urgent decisions are required. Sometimes the carer or escort sent with a patient is a nephew or niece chosen because they have a good command of English or experience with city life. Such an individual may, however, be quite inappropriate in cultural terms: if, in 
reaching a decision, the patient's "story" needs to be told (clinical history, examination and investigations), the nephew or niece may simply disappear, because they know they do not have the right to such information.

\section{Death and dying}

The ceremonies around death are extremely important to Indigenous people and take precedence over all other activities. Correct ceremonies should be held, with the correct people present, and the whole person must be buried or disposed of (depending on individual communities). If a body is to be removed from hospital to a homeland site there are likely to be both funding issues (no authorisation of funding for air transport) and cultural issues (an initiated ceremony person should accompany the body). The frequency of deaths in Indigenous communities can constitute a significant drain on community financial resources, as many individuals contribute to such costs.

Dying in a house may mean that the family cannot reoccupy it for a period of time. In some communities the patient will be taken outside to lie on the earth under a rough shelter for the last days or hours. Many communities employ a ritual of smoking a house or structure in which a patient has died, to purify it and cleanse it of bad spirits.

Memory persists of traditional funeral rites, such as were described by anthropologists in earlier times, though many (such as the preservation of a body by smoking) have been abandoned. The custom of self-mutilation, with the drawing of blood to demonstrate depth of grief, continues in some places.

\section{Implications for palliative care}

- When an Indigenous person dies away from the homeland the body will need to be escorted and taken back to the homeland.

- It is culturally appropriate to allow the "smoking" of a room in which a patient has died, even a hospital ward.

- It is important that all parts of a "body" be sent back: amputated limbs, gangrenous fingers, hair shaved to eliminate lice and clothes worn at death or worn in hospital are deemed important parts of the person. Such items need to be collected and stored appropriately.

\section{Conclusion}

In spite of the multiple losses and hardships endured by Indigenous Australians, a remarkable resilience and a pride in their surviving culture is apparent in many places, and non-Indigenous Australians have gradually been led to a greater respect and admiration for the people their forefathers almost completely destroyed.

"Respect" is a word that conveys many aspects of the appropriate approach to healthcare and palliative care for Indigenous Australians: respect for the terrible history of displacement, dispossession and violence that characterised white-black relations over generations; respect for different meanings of "family"; respect for the suspicion and discomfort commonly felt by Indigenous people required to enter major healthcare institutions, and the need for Indigenous

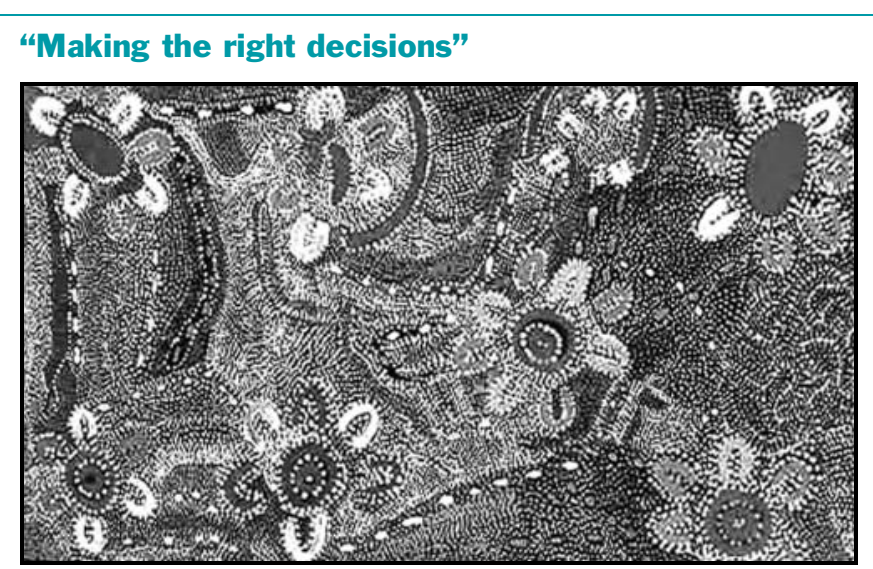

The palliative care service in central Australia created an Aboriginal art project to develop relevant teaching and learning tools. Aboriginal artists from different language and cultural groups were invited to paint their stories about "finishing up". This painting, "Making the right decisions" by Kumantjay Miller, illustrates the complexities of end-of-life decision making for Aboriginal patients living in remote communities who must travel long distances for hospital care. ${ }^{9}$

ownership, management and staffing of more acceptable healthcare facilities; and respect for the need to "sit down" with patients and family members, giving enough time and space to hear how needs are expressed and to bring familybased decisions into professional-led care plans. The inclusion in a palliative care team of an Indigenous health worker will usually be of great value in facilitating team and personal interactions with Indigenous people.

\section{Acknowledgements}

Bev Dershow and Simon Murphy of the Top End palliative care team and Aboriginal informants Major Sumner (Adelaide), Alan Sambono and Lorna Fejo (central Australia) contributed important insights to the preparation of this paper.

\section{Competing interests}

None identified.

\section{References}

1. Rowley CD. The destruction of Aboriginal society. Ringwood, VIC: Penguin Books, 1972

2. Maddocks I. Palliative care on the margins. Prog Palliat Care 1999; 7: 107-108.

3. Wenitong M. Cultural issues in health delivery. RACP News 2003; 22: 6-8.

4. European Network for Indigenous Australian Rights. Who is Aboriginal? Available at: www.eniar.org/culture.html (accessed Aug 2003).

5. Hayman N. Indigenous health today. RACP News 2003; 22: 5-6.

6. Kaul R. Racism and health: Australia's Aboriginals suffer disproportionate burden of ill health. BMJ 2003; 326: 880-881.

7. National Indigenous Palliative Care Needs Study. Newsletter No. 3. January/ February 2003. Available at: http://member.telpacific.com.au/ksa/ Newsletter_3.pdf (accessed Aug 2003).

8. Prior D. Palliative care in marginalised communities. Prog Palliat Care 1999; 7 : 109-115.

9. Fried $O$. Many ways of caring: reaching out to Aboriginal palliative care clients in central Australia. Prog Palliat Care 1999; 7: 116-119.

10. Understanding morphine. Mt Isa: Mt Isa Palliative Care Service, 2001.

11. Fenwick C. Pain management strategies for health professionals caring for central Australian Aboriginal people. Canberra: Commonwealth Department of Health and Aged Care, 2001.

12. Williamson P. "Let me die in my country": palliative care needs of Aboriginal people in the Kimberley and Pilbara regions of Western Australia. Broome: Department of Human Services and Health, Western Australia, 1996.

(Received 5 Jun 2003, accepted 29 Jul 2003) 